\title{
A Mode Design Research On Ubiquitous Learning
}

\author{
Yang $\mathrm{Xu}^{1}$ Pan Feng $^{1}$ \\ ${ }^{2}$ School of Economics and Management Beijing University of Posts and Telecommunications
}

\begin{abstract}
The emergence of ubiquitous technologies has completely reshaped the area of education in recent years. Mobile devices can be used to promote learning anywhere and anytime, to foster lifelong learning and knowledge sharing, or to promote building a learning society. This paper is to describe the basic elements of ubiquitous learning and to design an effective ubiquitous learning mode which can utilize the technology of ubiquitous computing and information to make a productive learning process. Then a typical ubiquitous learning mode is given. The paper might be useful for anyone interested in designing, preparing and implementing a ubiquitous learning system.
\end{abstract}

Keywords: ubiquitous learning; ubiquitous learning mode; elements of ubiquitous learning

\section{Introduction}

The growth of Information and Communication Technology has completely reshaped the area of education in recent years, especially the advances in wireless networking and mobile internet access technologies. And the rapid development of cloud computing and ubiquitous computing means people today are no longer limited to certain learning environments in their lives, which means learning can take place at any time and at any place. Due to the popularity of mobile technology and the sensor technology people learn as if they are in a real classroom environment through context-aware applications.

Recent developments on mobile devices and ubiquitous computing enable new opportunities for learners. The ubiquitous learning system makes it happen that the learners are able to access education resources related to their particular context over the wireless network or high-speed broadband network and have them displayed immediately on their learning platform, which satisfies the requirements of personalized learning. Curtis, Luchini, Bobrowsky and Quintana defined the following features for ubiquitous learning: permanency, accessibility, immediacy, interactivity, situating of instructional activities $^{[1]}$. Ubiquitous learning is enhanced with intelligent environment and context awareness and emphasizes the provision of suitable courseware at an appropriate time and place, which plays a very important role when it comes to the life-long learning and improvement of future learning effectiveness.

\section{Related Research}

The ubiquitous learning is closely related to the development of ubiquitous computing (also called as pervasive computing) and sensor technology. Ubiquitous computing is a rapidly developing area of ICT, which refers to the integration of ICT into people's lives and environments. Mark Weiser coined the term 'Ubiquitous Computing' in 1991, who predicted that the technology itself will become invisi- 
ble and networked into our daily lives ${ }^{[2]}$. However, ubiquitous technology and its applications have had an extensive development in recent years because of the rapid growth in wireless sensor technology [3] [4] [5]. Mobile devices, embedded systems, wearable computers, sensors, Radio Frequency Identification (RFID) tags, etc. make the environment pervasive. In the near future, even learners don't need to carry the mobile devices; the environment itself will guide them to avail the services as per the user's needs. Ubiquitous learning helps in the development of knowledge society ${ }^{[6]}$. The objective is a society with access to knowledge and learning for everyone ${ }^{[7]}$. Ubiquitous technologies and mobile devices create such opportunities for flexible and collaborative learning modalities, anywhere and anytime, at the same time ensuring close relationships between learning in the workplace, at home, at school and/or in a community by anyone on any subject (the Tim Kelly's 4A vision: "anywhere, anytime, by anyone and anything").

\section{Basic Elements}

Basic elements of ubiquitous learning system are learner, devices, network, platform and resources. Figure 1 shows basic elements of an effective ubiquitous learning.

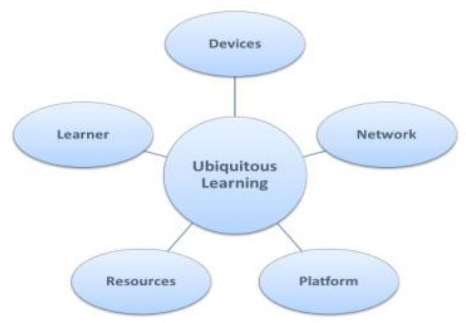

Fig. 1: Basic elements of ubiquitous learning. Basic elements are described below:

\subsection{Learner}

Ubiquitous learning is based on User-
Centered Design in order to provide more convenient learning environment and context-aware content to meet the learner's interests and needs. All the other elements serve to the learner. The learner can be divided into two kinds, individual learner and enterprise learner. Today lifelong learning is an inevitable trend, and individual learning is becoming a kind of inevitable need.

\subsection{Devices}

Terminal devices are the tools used in ubiquitous learning, and also are the indispensable element in ubiquitous learning. And the dependence which ubiquitous learning has on learning tools is more obviously than ever before. The function and characteristic of the learning tools will directly influence the method and content in education. Ubiquitous learning decreases limitation of learning location with the mobility of general portable devices, including laptop computers, tablet computers, smart phones, pocket computers, portable media players, MP3 players, video players, pads and so on.

We can evaluate the learning devices from seven aspects: mobility, accessibility, convenience, interactivity, study auxiliary, scalability, and application costs.

\subsection{Network}

The network technology is an important part of the elements in ubiquitous learning, which provides the indispensable support. With the rapid development of communication technology, network used by mobile devices differs from each other, and mainly can be divided into cable connection and wireless connection. Cable connection offers high speed access at a fixed place while wireless network communication technology is used for internet and intranet access and available in almost every mobile device today. Common wireless communication tech- 
nology mainly includes GPRS, Edge, Bluetooth, 3G Technology and 4g Technology. By solving scanning problems faced in accession to education resources by mobile devices, online connection has increased the interests in network technologies and their usage.

\subsection{Platform}

The ubiquitous learning platform provides extensive courseware and applications for learners through network, which is the main carrier of the service and support in the ubiquitous learning. Terminal device structure, network structure and the difference between education resources will influence the design of the platforms. A good platform should be able to unite the difference between resources, network and equipment in order to provide a friendly and consistent experience for learners. The development of cloud computing technology and ubiquitous technology makes it possible that the ubiquitous learning system provides seamless connection and consistent experience for learners under any circumstances.

\subsection{Resouces}

The ubiquitous learning resources are the foundation of all the learning activities, including courseware content and applications. Here the resource is present in the objects in the whole world. Courseware content can be transferred to the learner in the form of images, text, sound or other format. Applications can make the learning activities more interesting and practical. Also all information is flexible and adaptable, allowing updates to be applied through network.

\section{Ubiquitous Learning Platform}

In this section, one of the typical ubiquitous learning application modes, the ubiquitous learning platform, is analyzed.
The ubiquitous learning platform system is used for storage and management of education resources and resources distribution. The main resources are the combination of various kinds of digital media, such as text, picture, audio and video, to present knowledge, information of study materials. Figure 2 shows the concept map of ubiquitous learning platform.

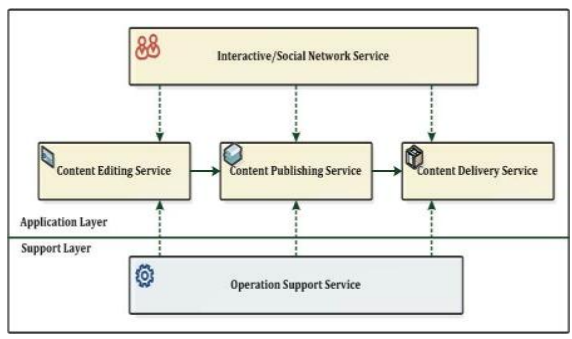

Fig. 2: Concept map of Ubiquitous Learning Platform.

The main function includes:

- Content editing service module: for content processing and editing, including content generation, content proofreading, content publishing, content submitting, content revocation.

- Content release service module: for content release, including content audit, content packet, content online, authorized management, content referral.

- Content delivery service module: for content distribution to the client or device, including content display, content order, content retrieval, content downloaded, content browsing, content delete, and content upgrade.

- Interactive/social network service module: used to provide interactions between system and users or user and user, including user registration, interactivity management and so on.

- Operation support system module: used for learning resources platform system support operations, including content management, release node management, content classification management, subscription manage- 
ment, billing accounting, payment clearing, CP management, channel management, terminal management, community management, user management, the inquiry statistics, advertising management, role management, rights management, ability management, monitoring.

\section{Conclusion}

Ubiquitous learning provides further flexibility for the learner to learn anytime, anywhere on the move, which marks a great step forward in education. The ubiquitous computing technologies and information and communication technologies have changed the traditional concept of learning so that we can do whatever we want, and can be immersed in learning experiences, which eventually will be incorporated into our daily lives. Even the recent developments in technologies foresee a day where learners don't even need a device to learn .

The paper focuses on the research of ubiquitous learning mode. Learner, devices, network, platform and resources are basic elements of the ubiquitous learning, which have to be considered when designing ubiquitous learning mode. Then a typical ubiquitous learning mode is given as a demonstration. It can be concluded that the paper might be useful for anyone interested in designing, preparing and implementing a ubiquitous learning system or anyone else who may look for a proper ubiquitous learning mode that exactly suits his or her demands. Further studies can take empirical study into account and details research needs to be added and completed.

\section{Acknowledgment}

This project is supported by "the Fundamental Research Funds for the Central Universities" (2011RC1010).

\section{References}

[1] Curtis, M., Luchini, K., Bobrowsky, W., Quintana, C., \& Soloway, E. (2002). Handheld use in K-12: A descriptive account. In Proceedings of IEEE international workshop on wireless and mobile technologies in education (WMTE’02) (pp. 23-30).

[2] V. Jones, and J. H. Jo, "Ubiquitous learning environment: An adaptive teaching system using ubiquitous technology.", In R. Atkinson, C.McBeath, D. Jonas- Dwyer and R. Phillips (eds.), Beyond the comfort zone: Proceedings of the $21 \mathrm{st}$ ASCILITE Conference, pp. 468 - 474, 2004.

[3] Chen, N. S., Kinshuk Wei, C. W., \& Yang, S. J. H. (2008). Designing a self-contained group area network for ubiquitous learning. Educational Technology \& Society, 11(2), 16-26.

[4] Huang, Y. M., \& Wu, T. T. (2011). A systematic approach for learner group composition utilizing U-learning portfolio. Educational Technology \& Society, 14(3), 102-117.

[5] Osman, M., El-Hussein, M., \& Cronje, J. C. (2010). Defining mobile learning in the higher education landscape. Educational Technology \& Society, 13(3), 3-11.

[6] Anastasios A. Economides, "Adaptive context-aware pervasive and ubiquitous learning", International Journal of Technology Enhanced Learning, Vol. 1, No 3, pp. 169-192, May 2009.

[7] Lytras, M.D. and Sicilia, M.A. 'The knowledge society: A manifesto for knowledge and learning', International Journal of Knowledge and Learning, Vol. 1, No. 1/ 2, pp. 1-11, 2005 